\title{
Ultrasound Imaging for the Upper Limb Nerves in CRPS: A Patient With Electrical Injury
}

\section{TO THE EDITOR}

A 31-year-old man was injured on the right arm by contact with a $380 \mathrm{~V}$ tension cable 3 weeks prior to presenting. The week before presenting he started to have severe pain and swelling on that arm. His medical history was otherwise noncontributory.

Physical examination revealed edema and discoloration on the right distal forearm and hand. Upper extremity ranges of motions (ROM) were painful on the right side. A neurological examination yielded widespread allodynia on the right arm. Muscle strength and deep tendon reflexes were normal bilaterally. Electrodiagnostic testing was performed for a likely diagnosis of peripheral nerve injury. Nerve conduction studies in the upper limbs were normal; however, while amplitude and latency of the sympathetic skin response were $1.46 \mathrm{mV}$ and 1.43 milliseconds on the left side, we could not obtain any response from the right side. Thereafter, substantial ultrasound imaging using a 7-12 MHz linear probe (Logiq P5, GE Healthcare, Wisconsin, US for the upper limb periph- eral nerves was performed. Median, ulnar and radial nerves were found to be enlarged on the right side (Fig. 1). Overall, the patient was diagnosed with early complex regional pain syndrome (CRPS) (1) and a physical therapy program including a contrast bath, transcutaneous electrical nerve stimulation, and gabapentin $600 \mathrm{mg} 3$ times a day were commenced. The patient was called for a control visit; however, since the patient's symptoms improved after the treatment, he was lost to follow-up thereafter.

CRPS can develop following an initiating noxious stimulus which is disproportionate to the inciting event (2). CRPS can also be seen following electrical accidents $(2,3)$. The relevant signs and symptoms usually start within a day of injury but are often delayed for days, weeks, or months (3). Herein, unexplained diffuse pain, allodynia/hyperalgesia, color or temperature changes decreased active ROM and diffuse edema may be some of the more common manifestations for its prompt diagnosis (2).

Fig. 1. Comparative ultrasound imaging (axial view) for median $(A, B)$, ulnar $(C, D)$ and radial $(E, F)$ nerves at mid-forearm (12 cm distal to the elbow crease), mid-forearm (12 cm distal to the elbow crease) and elbow levels, respectively.

Right sided images correspond to the left (healthy) side of the patient whereby black arrowheads indicate the normal nerves and left sided images correspond to the right (injured) side of the patient whereby white arrowheads show edema (swelling) in all the three nerves. ( $u$ : Ulnar nerve)

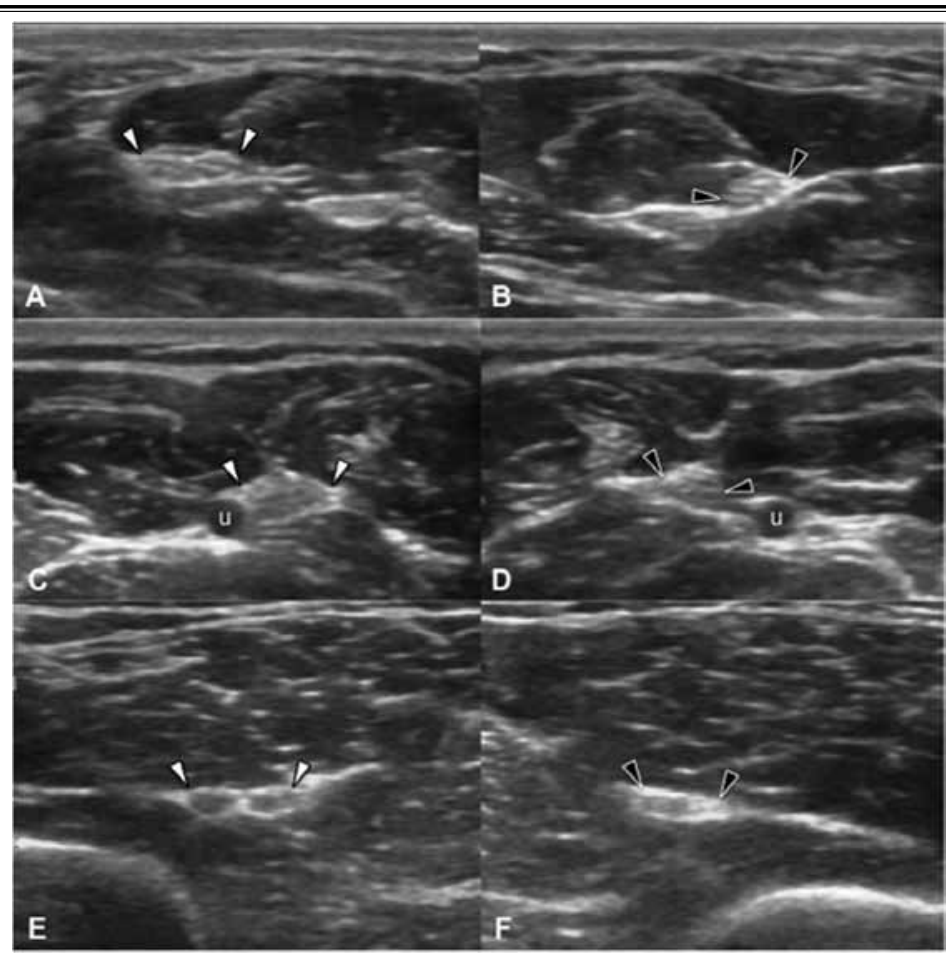


Electrical injury can affect all organ systems in the early or late period depending on the distribution and intensity of the electrical insult (4). Likewise, CRPS can occur as a result of peripheral nerve damage due to high voltage ( $>1000 \mathrm{mV}$ ) electrical injuries. In our case, the injury was due to low voltage (generally used in domestic settings), and the nerve conduction studies showed no evidence of neuropathy. Therefore, the clinical scenario was more likely to be early CRPS, whereby ultrasound imaging has shown some morphological changes as well. One possible explanation would be that the electrical injury followed a path of least resistance fibers (i.e., $C$ fibers and sympathetic nerve fibers) (4), which are not evaluated with routine electrodiagnostic tests. It is also suggested that electrical impulses ascend up and down the peripheral nervous system by the nociceptive $C$ fibers (5). Accordingly, abnormally high rate firings of electrically injured nerve fibers might have led to CRPS in our case.

Overall, presenting this patient of ours, we underscore the potential role of ultrasound in the diagnosis of CRPS which is otherwise based on mainly clinical evaluation. Being a convenient imaging modality, ultrasound can readily be used as a diagnostic adjunct for morphological confirmation/classification of the neural insult especially when the neural involvement is widespread $(6,7)$.
Murat Kara, MD

Associate Professor

Ankara Physical Medicine and Rehabilitation

Training and Research Hospital

Sıhhiye, Ankara, Turkey

Süha Yalçın, MD

Ankara Physical Medicine and Rehabilitation

Training and Research Hospital

Sıhhiye, Ankara, Turkey

E-mail: suhayalcin@yandex.com

Fevziye Ünsal Malas, MD

Ankara Physical Medicine and Rehabilitation

Training and Research Hospital

Sıhhiye, Ankara, Turkey

Tülay Tiftik, MD

Ankara Physical Medicine and Rehabilitation

Training and Research Hospital

Sıhhiye, Ankara, Turkey

Levent Özçakar, MD, Professor

Hacettepe University Medical School

Department of Physical Medicine and Rehabilitation

Ankara, Turkey

\section{References}

1. Harden RN, Bruehl S, Stanton-Hicks $\mathrm{M}$, Wilson PR. Proposed new diagnostic criteria for complex regional pain syndrome. Pain Med 2007; 8:326-331

2. Fish RM. Electric injury, Part II: Specific injuries. J Emerg Med 2000; 18:27-34

3. Fu PK, Hsu HY, Wang PY. Delayed reversible motor neuronopathy caused by electrical injury. J Chin Med Assoc 2008; 71:152-154
4. $\quad$ Kim CT, Bryant P. Complex regional pain syndrome (type I) after electrical injury: a case report of treatment with continuous epidural block. Arch Phys Med Rehabil 2001; 82:993-995

5. Smith HS, Albrecht PJ, Rice FL. Complex regional pain syndrome pathophysiology. In: Smith H (ed) Current therapy in pain, 1st edn. Elsevier Saunders, Philadelphia 2009 p 295
6. Kara M, Özçakar L, De Muynck M, Tok F, Vanderstraeten G. Musculoskeletal ultrasound for peripheral nerve lesions. Eur J Phys Rehabil Med 2012; 48:665-674

7. Kara M, Yilmaz A, Ozel S, Ozçakar L. Sonographic imaging of the peripheral nerves in a patient with neurofibromatosis type 1. Muscle Nerve 2010; 41:887-888 